\title{
SEJARAH SINGKAT STUDIO FOTOGRAFI POTRET DI YOGYAKARTA 1945-1975: SUMBER DAYA MANUSIA, TEKNOLOGI, DAN KREASI ARTISTIKNYA
}

\author{
Irwandi, G.R. Lono Lastoro Simatupang, dan Soeprapto Soedjono \\ Program Studi Pengkajian Pertunjukan dan Seni Rupa \\ Sekolah Pascasarjana UGM \\ Jln. Teknika Utara, Pogung, Sleman, Yogyakarta 55281 \\ No. HP. 081328656252, E-mail: insinyurwandi@yahoo.com
}

\begin{abstract}
ABSTRAK
Penulisan sejarah fotografi di Indonesia pascakemerdekaan boleh dikatakan masih belum banyak dilakukan. Catatan sejarah yang ada lebih mengarah pada perjalanan fotografi dalam merekam momen pra dan pascakemerdekaan, yang sebagian besar bersumber pada foto-foto dokumen milik IPPHOS (Indonesian Press Photo Service). Ini berarti, masih dibutuhkan penelusuran lebih lanjut guna merekonstruksi sejarah fotografi Indonesia dalam bidang yang lain, studio misalnya. Tulisan ini membahas perkembangan studio foto di Yogyakarta pascakemerdekaan. Hal yang dijadikan fokus utama ialah sumber daya manusia, teknologi, dan upaya-upaya artistik yang dilakukan dalam praktik studio foto masa itu. Penelusuran sejarah dilakukan dengan metode wawancara kepada pemilik studio, praktisi fotografi yang merupakan pelaku dan saksi sejarah studio fotografi pascakemerdekaan. Observasi juga dilakukan guna mengetahui lebih detail tentang upaya-kreatif yang dilakukan pihak studio foto dalam mewujudkan karyanya. Dapat disimpulkan bahwa aspek teknologi memberi pengaruh besar dalam proses perwujudan karya foto studio. Dapat terlihat bagaimana para pelaku usaha studio foto mengatasi keterbatasan teknologi.
\end{abstract}

Kata kunci: sejarah, studio fotografi potret, Yogyakarta

\section{ABSTRACT}

A Brief History of Portrait Photography Studio in Yogyakarta 1945-1975: Human Resources, Technology and Artistic It's Creation. Writing the history of photography in the post-independence Indonesia arguably still not been done. The historical record that there are more leads on a photography trip in the pre and post-independence record the moments, which are largely sourced on the photographs of documents belonging IPPHOS (Indonesian Press Photo Service). This means, still needed further investigation in order to reconstruct the history of photography Indonesia in other fields, for example studio. This paper discusses the development of a photo studio in Yogyakarta post-independence. It is used as the primary focus is human resources, technology, and the efforts made in the artistic practices of the past photo studio. Search history conducted by interview to the owner of the studio, photography practitioner who is the perpetrator and witnesses photography studio post-independence history. Observations were also conducted to determine more details about the creative efforts that made the photo studio in realizing his work. It can be concluded that the technological aspects of great influence in the process embodiment studio photographs. It is noticeable how the photo studio business operators overcome the limitations of technology.

Keywords: history, photography studio portrait, Yogyakarta 


\section{PENDAHULUAN}

Yogyakarta merupakan salah satu kota yang menjadi bagian penting dalam masa perkembangan awal fotografi di Indonesia (saat itu masih bernama Hindia Belanda). Sejumlah bukti yang menguatkan pernyataan tersebut antara lain karya tulis dari Knapp (1999), Hacks dan Wachlin (2004), Groeneveld (1989), dan terakhir oleh Strassler (2010). Dalam ketiga karya tulis tersebut selalu ada contoh-contoh foto dan ulasan singkat tentang fotografi di Yogyakarta. Dalam buku Toekang Potret: 100 Jaar Fotografie in Nederlands-Indië karya Groeneveld tercatat bahwa hingga tahun 1940, setidaknya ada 20 (dua puluh) studio foto di Yogyakarta (Groeneveld, 1989). Setelah masa itu, tidak banyak ditemukan catatan-catatan sejarah yang meyakinkan mengenai hal-hal penting yang berkaitan dengan studio-studio foto di Yogyakarta. Namun, beberapa gambaran dapat diperoleh dari hasil penelitian Soedjono, Marah, dan Rusli tentang Salon Foto Indonesia (1999); penelitian Strassler (2010) yang mengangkat budaya dokumentasi foto di Jawa; dan tulisan Marah (2008) yang secara garis besar menggambarkan perjalanan fotografi Indonesia dalam kurun waktu 150 tahun.

Tujuan utama artikel ini ialah memberi gambaran tentang beberapa hal yang dipandang penting dalam menentukan wujud foto potret studio di Yogyakarta pascakemerdekaan (tahun 1940-an hingga tahun 1970-an). Hal-hal yang akan dibahas berkaitan dengan (1) teknologi/ peralatan; (2) sumber daya manusia di studio foto; (3) wujud produk foto studio.

Selain sumber-sumber yang telah disebutkan di paragraf sebelumnya, artikel ini juga menggunakan data primer yang didapatkan dari pelaku dan saksi sejarah studio foto di Yogyakarta. Data-data dihimpun melalui metode wawancara dan observasi. Hasil penelusuran akan disajikan dalam bentuk deskriptif analitis.

\section{PEMBAHASAN}

Studio-studio foto milik para pengusaha Cina dan beberapa pengusaha dari Jepang telah ada di Yogyakarta lebih dari satu dekade sebelum kemerdekaan (Groeneveld (Ed.), 1989).

Studio-studio milik orang-orang Cina pada saat itu merupakan bisnis keluarga yang dijalankan secara turun-temurun. Anak-anak ataupun saudara dari pemilik studio ikut membantu menjalankan bisnis dan mendapatkan peran penting dalam studio tersebut. Dalam perkembangan selanjutnya keturunan ataupun para saudara dari si pemilik studio meneruskan usaha studio yang telah ada, bahkan mendirikan studio baru, ketika mereka mulai berkeluarga.

Salah satu contohnya dapat dilihat pada perkembangan Studio Liek Kong yang terletak di Tugu Kidul (sekarang Jalan Mangkubumi). Studio tersebut didirikan pada tahun 1930 dan berhenti beroperasi pada akhir dekade 80 . Dua keturunan Tjen Hauw (pendiri Studio Liek Kong) kemudian mendirikan usaha studio foto sendiri dan masih beroperasi hingga saat ini. Kedua studio yang dimaksud adalah Artha Foto yang didirikan oleh Sapto Handoyo dan Duta Foto yang didirikan oleh Tun Yulianto. Duta Foto dan Artha Foto sama-sama berlokasi di Jalan Urip Sumoharjo atau yang lebih dikenal dengan nama Jalan Solo.

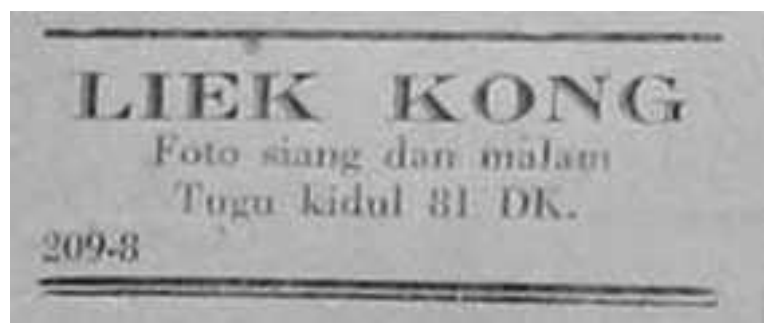

Gambar 1. Iklan Studio Liek Kong tahun 1960

(Harian Kedaulatan Rakyat, 16 Agustus 1960) 
Sementara itu, Strassler (2010:83) mencatat bahwa Tik Sun adalah salah satu studio foto di Yogyakarta yang didirikan pada tahun 1950. Studio Tik Sun didirikan oleh Untung Soesanto, yang sebelumnya berprofesi sebagai juru tusir pada usaha percetakan majalah di Bandung. Istri Untung Soesanto yang bernama Gianti Indartini (Yang Jing Ie), kini 82 tahun, adalah salah satu keponakan Tjen Hauw, pemilik Studio Liek Kong.

Setelah tahun 1966, Studio Tik Sun berganti nama menjadi Indah Foto (2010:75). Pergantian nama studio disebabkan adanya kebijakan pemerintah Indonesia saat itu untuk mendorong asimilasi antara masyarakat Cina dan pribumi. Studio Indah Foto pun terus beroperasi, bahkan hingga pendirinya wafat pada tahun 2002.

Sesudah Untung Soesanto wafat, usaha studio foto masih diteruskan oleh Gianti Indartini bersama anak-anaknya. Namun, pada akhirnya studio tersebut ditutup pada tahun 2010 karena usia Gianti Indartini yang sudah lanjut dan anak-anaknya sudah mendirikan studio foto sendiri. Kini ada tiga keturunan Untung Soesanto yang masih menjalankan bisnis studio foto. Dua di antaranya beroperasi di Kota Yogyakarta dan yang satunya di Kota Wonogiri (Wawancara dengan Gianti Indartini, pendiri Studio Tik Sun, 1 Oktober 2013).

Para penerus usaha studio foto milik pengusaha Cina mendapatkan ilmu fotografi dari pengalaman saat membantu usaha orang tua mereka (Wawancara dengan Stephanus Setiawan, praktisi fotografi, 27 September 2013).

Contohnya Sapto Handoyo, ia mulai membantu usaha orang tuanya sejak berumur 12 tahun. Ia pun masih ingat banyak hal tentang fotografi masa itu yang serba terbatas dan jauh berbeda bila dibandingkan dengan fotografi masa kini.
Contoh perbedaan teknologi fotografi zaman itu tampak dari penuturan Handoyo sebagaimana berikut. "Wah... dulu kameranya bikin sendiri, dari kayu. Yang kita beli hanya lensa, itu lensa merk Zeiss Ikon. Obat cuci cetak juga bikin sendiri, karena kalau beli yang Kodak pasti mahal (Wawancara dengan Sapto Handoyo, pemilik Artha Foto, 1 Oktober 2013"). Masih menurut Handoyo, dahulu orang hanya lazim memesan foto ukuran $3 \times 4$ $\mathrm{cm}$ dan 4x6 cm. Ukuran foto yang lebih besar sebenarnya sudah ada, tapi jarang diperlukan.

Saat itu pun belum banyak istilah untuk produk foto yang ditawarkan kepada pelanggan. Situasinya sangat berbeda dengan sekarang. Sebagaimana penuturan Handoyo yang berikut.

"Dulu itu belum ada macem-macem, orang kalau mau foto datang, terus bilang mau foto $3 \times 4 \ldots$ foto zaman dulu tertib, rapi, simetris, kepala harus kelihatan utuh, tidak ada kepala 'dipotong' seperti sekarang. Orang bisa marah-marah. Nggak kayak sekarang" (Wawancara dengan Sapto Handoyo, 1 Oktober 2010).

Teknologi dan kecenderungan fotografi potret studio pada era 1940-1970'an amat berbeda bila dibandingkan dengan kondisi fotografi dewasa ini. Pada era tersebut teknologi fotografi masih cenderung tertutup. Artinya, belum banyak orang yang memiliki kamera, terlebih orang yang memahami teknologinya. Bahkan, pengetahuan fotografi seolah-olah menjadi rahasia bagi kalangan masyarakat awam. Pengetahuan fotografi hanya diketahui oleh sebagian kalangan, yakni orang-orang yang masih memiliki hubungan kekerabatan dengan pemilik studio foto. Handoyo merupakan contoh bagaimana sumber daya manusia foto studio pada era 1940-1970'an mendapatkan 
pengetahuan fotografi secara otodidak, karena adanya faktor keturunan dan kekerabatan.

Mau tanya apa? Fotonya, kameranya, prosesnya? Saya itu umur 12 tahun sama papi saya (Liek Kong) udah diajak ke kamar gelap, lihat bak cuci itu segini (sambil menunjuk ke leher). Dulu obatnya buat sendiri, ada metol, quinon (hydroquinone). Kalau beli yang Kodak mahal (Wawancara dengan Handoyo, 1 Oktober 2010).

Teknologi, bahan, dan cara penggunaan kamera sebagai salah satu peralatan utama untuk menghasilkan selembar foto potret saat itu pun jauh berbeda dengan sekarang. Hingga akhir tahun 1960-an, dari sisi ukuran kamera yang digunakan untuk pembuatan potret di studio adalah kamera large format yang terbuat dari kayu. Dari sisi konstruksi dan ukurannya, kamera tersebut termasuk dalam jenis view camera yang namun tidak dilengkapi fasilitas film movement (bidang film yang dapat digerakgerakkan) dan lens movement (bidang lensa yang dapat digerak-gerakkan), yang mencakup swing, tilt, dan shift. Hal ini terjadi karena badan kamera tersebut dibuat sendiri, sebagaimana dipaparkan oleh Suljantoro atau lebih dikenal dengan Agus Leonardus berikut ini.

"Sama kurang lebih, sebenarnya kan prinsip kerja kamera itu yang gini gini sangat sederhana sekali ya, cuma kamera obscura berlensa, udah gitu aja, sangat sederhana, jadi yang saya amati kamera kamera kayu itu akhirnya banyak bikinan tukang kayu. Itu jadi yang bikin bukan pabrik-pabrik besar itu, hanya lensanya tetap dari pabrik tapi body-nya, tripod-nya bikinan tukang kayu. ...itu aja, prinsip kerjanya kan sangat sederhana sekali. Jadi dari dulu kan banyak tukang kayu keturunan Cina, yang dari daratan Cina kan datang ke Indonesia itu kan ada tuh ya kayak-nya mereka yang bikin. Walaupun mungkin yang pesen orang lain ya tapi mereka yang bikin, jadi kalok cari merknya nggak ada merk-nya, kadang kadang yang ada penjualnya, jadi di situ ada semacam emblem gitu ya dari logam itu nama penjualnya bukan nama pabriknya" (Wawancara dengan Agus Leonardus Sujantoro, fotografer, 8 Oktober 2013).

Penggunaan large format camera memberikan keuntungan tersendiri. Keuntungan menggunakan kamera large format dalam konteks ini terletak pada ukuran film yang lebih besar. Maka tidak mengherankan, jika foto-foto yang dihasilkan dari view camera memiliki detil gambar yang sangat baik. Namun saat itu, lampu kilat belum lazim digunakan untuk studio.
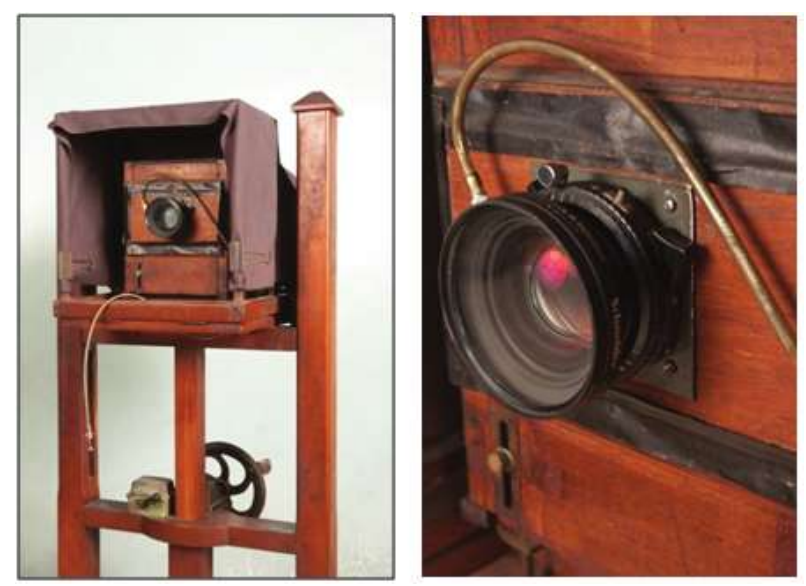

Gambar 2. Kamera kayu yang digunakan di Studio Tik Sun Koleksi Cung Mintarto/Menara Foto Wonogiri (Foto: Rudy Sebastian) 


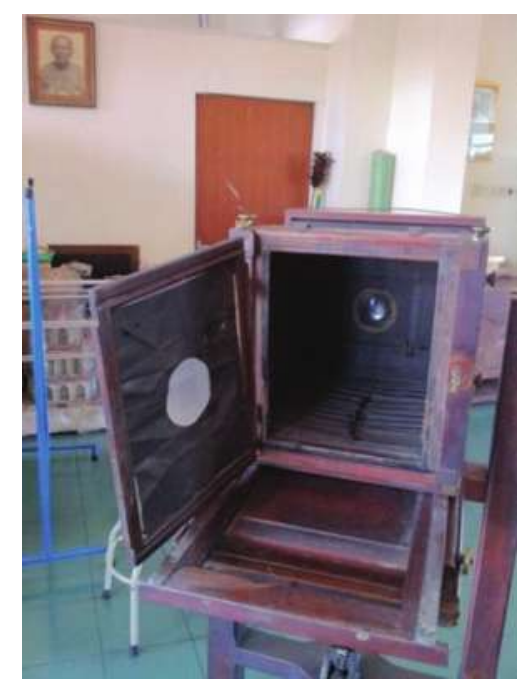

Gambar 3. Bagian belakang kamera kayu format besar koleksi Delanggu Foto,

(Foto: Irwandi)

Studio-studio biasanya menggunakan lampu pijar yang dirangkai sendiri untuk pencahayaan pada saat pemotretan. Sebagaimana dituturkan Cung Indarto, "Papi itu orangnya suka bikin-bikin sendiri mas, lampu rakit sendiri, kreativitas sendirilah" (Wawancara dengan Cung Mintarto, penerus studio Tik Sun, pemilik Menara Foto, Wonogiri, 21 Oktober 2013).

Konsekuensinya, bukaan diafragma yang digunakan harus besar. Pilihan ini menyebabkan ruang ketajaman lensa menjadi melengkung, tidak rata. Untuk itu, pada pemotretan berkelompok (misalnya foto keluarga), sitter harus berdiri membentuk barisan yang melengkung mengikuti ruang ketajaman lensa.

"Karena lensa dulu kan masih nggak bagus, jadi kalok kita lurus ya, ini kameranya d sini jarak sini (kiri) ke sini (kanan) dan tengah kan beda ya ruang tajamnya kan, jadi suruh melengkung supaya jaraknya sama, gitulah (Wawancara dengan Suljantoro, 8 Oktober 2013).

Walaupun sesungguhnya kamerakamera kayu tersebut dapat digunakan untuk film berformat besar ( $8 \times 10$ inci), dalam praktiknya film yang digunakan adalah film medium (format 120). Film yang digunakan pun masih terbatas pada film hitam putih karena pada saat itu film berwarna belum lazim digunakan di Yogyakarta. Film berwarna diketahui mulai digunakan secara luas di Yogyakarta sejak pertengahan dekade 1970-an (Wawancara dengan Herri Gunawan, pemilik Studio Herry Photo, 30 September 2013).

Kondisi teknologi yang masih sangat merepotkan, ditambah pula dengan kecenderungan terbatasnya akses fotografi di kalangan masyarakat awam, menyebabkan ketergantungan masyarakat pada studio foto lumayan tinggi. Pelanggan yang datang ke studio foto tidak terbatas hanya dari Kota Yogyakarta, tetapi juga datang dari daerah/ desa-desa di pinggiran Yogyakarta. Tidak jarang mereka datang secara bersama-sama, diantar dengan mobil bak terbuka, hanya untuk berfoto di studio.

"Dulu yang namanya pas foto itu nggak gampang... nggak gampang juga. Karena pas foto itu kalok mau bener yang namanya pas foto itu butuh yang namanya detail juga terus shadownya reasonable, kalok perlu nggak ada... kenapa? Supaya makin tampak semuanya karena itu yang namanya $I D$ itu memang harus semua tampak. Nah dulu orang sampek antri antri kalok pas foto saya inget di Hwa Sin saya bantu itu sering... Mas sopo? Pak sopo ayo no. 5, koyo dokter persis, terutama pada hari tertentu itu dulu langganannya bahkan saya sampek ngerti semua, sampek daerah Bantul, Imogiri. Itu kalok datang 1 colt. Pake colt, iya.... (Wawancara dengan Johnny Hendarta, pemilik Studio CPC Yogyakarta, 22 Januari 2014).

Perlengkapan dasar studio foto pada dekade 1950-an tidak jauh berbeda dengan saat ini, bila dilihat dari sisi fungsinya. Setidaknya sebuah studio foto potret dilengkapi dengan seperangkat kamera, lampu studio, gambar 
latar, ruang ganti, dan sebuah kamar gelap untuk mencetak foto. Gambar latar yang digunakan di studio saat itu didapatkan dari penjual yang datang menawarkan gambar latar di studio. Gambar latar tersebut kemudian dibingkai (span), berbeda dengan saat ini, yang mana gambar latar studio lazimnya dapat digulung. Hal ini diutarakan oleh Oetomo, salah satu penerus studio Delanggu yang dulu bernama Shanghai Foto. "Biasanya ada yang datang, nawarin background. Dulu itu background foto dibingkai... ukurannya sekitar 2 × 3 meter, bolak balik" (Wawancara dengan Tri Poernomo Oetomo, Penerus Shanghai foto (sekarang Delanggu Foto), 10 September 2103.

Untuk lampu studio dahulu masih mengandalkan sumber cahaya continuous atau sumber cahaya yang menyala secara terus-menerus, yaitu photo flood atau lampu khusus untuk studio foto yang berkekuatan 500 watt, lampu pijar, ataupun matahari (Hendarta, 11 Juni 2014). Sementara untuk peralatan cetaknya, studio foto pada masa itu menggunakan enlarger yang dirakit sendiri.

Namun keterbatasan teknologi fotografi saat itu, pada kenyataannya tidak menghalangi pengelola studio-studio foto untuk tetap memaksimalkan hasil-hasil foto yang akan diserahkan kepada pelanggan. Selain melakukan penataan cahaya pada saat pemotretan dan pemilihan gambar latar sesuai dengan yang diinginkan oleh konsumen, upaya perbaikan kualitas foto juga dilakukan pada film negatif (klise) yang akan dicetak. Mereka menyebutnya dengan istilah tusir negatif. Perbaikan itu biasanya berkaitan dengan pembersihan foto dari noda dan reduksi bagian gelap (shadow) pada foto. Reduksi shadow dilakukan agar foto yang dihasilkan tampak bersih, natural, dan tidak terlalu kontras (Hendarta, 11 Juni 2014).
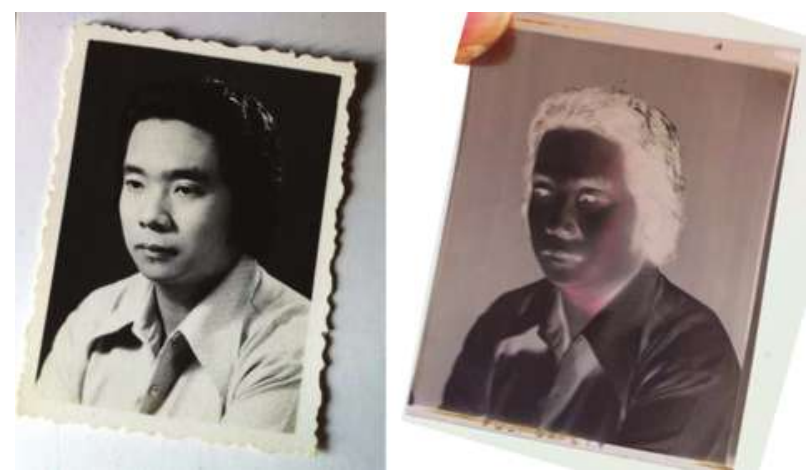

Gambar 4. Foto dan negatif yang sudah ditusir. Hasil pemotretan di Studio Tik Sun, 1970-an koleksi S. Setiawan (Foto: Irwandi)

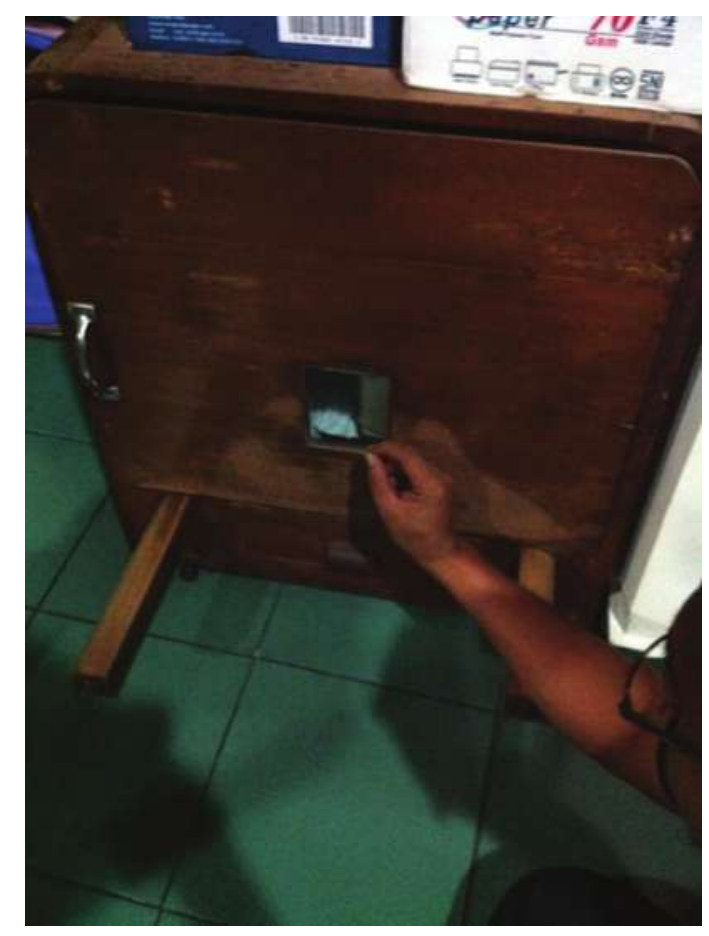

Gambar 5. Meja/lemari tusir foto Koleksi Delanggu Foto.

(Foto: Joko Suwarno)

Dulu pas foto yang paling kita perhatiin lighting itu ya, jangan nanti muncul di sini (di bawah dagu) bayangannya jangan sampai kaya jenggot. Kalok pingin hitam putih emang separo gini (sebelah kanan atau kiri). Tapi kalok dua duanya kan bayangannya agak sensitif. Itu sebenernya bisa diilangin juga dengan ditusir. ...khusus, tidak semua orang bisa, dulu di-lapisin minyak dulu, minyak kayak gondorukem biar pensilnya 
nempel, pensilnya runcing sekali dan itu ada pake B, lupa saya $\mathrm{B}$ atau $\mathrm{H}$ untuk keempukannya (Handoyo, 1 Oktober 2013).

Upaya itu dilakukan oleh tenaga tersendiri yang telah terlatih, dilakukan dengan bantuan pensil dan pewarna khusus. Untuk menghilangkan noda pada film negatif, cara yang dilakukan ialah dengan memberi warna merah transparan pada bagian-bagian tertentu di film negatif yang akan dicetak. Warna merah dalam proses cetak foto hitam putih diketahui memang dapat mengurangi intensitas cahaya yang terekam di atas kertas foto karena kertas foto hitam putih tidak peka terhadap spektrum merah. Dengan demikian, pemberian warna merah di negatif (klise) foto akan membuat bayangan pada foto tidak terlalu gelap.

Selain menusir film negatif, studiostudio foto pada masa itu juga menyediakan layanan tusir/pewarnaan pada foto hitam putih. Tujuannya untuk mewarnai foto hitam putih menjadi sehingga terlihat lebih realistik. Akan tetapi, jumlah foto yang diwarnai tidak banyak. Pewarnaan pada foto hitam putih pun sering kali hanya diterapkan di bagian-bagian penting, yaitu wajah dan pakaian. Jasa ini saat itu cukup banyak peminatnya, sebagaimana dituturkan oleh Sapto Handoyo.

O..itu untuk pewarna, beda lagi, untuk foto yang udah jadi terus diwarna. Black and white terus diwarna. Tapi kan warnanya ngak bisa dimensi. Banyak (peminatnya). Warnanya sederhana, wajah kayak pink lipstik warnanya gitu gitu aja. itu (harganya) tersendiri, dulu yang mengerjakan Aris barang tapi meninggal, Aris Hwa Sin (Handoyo, 1 Oktober 2013).

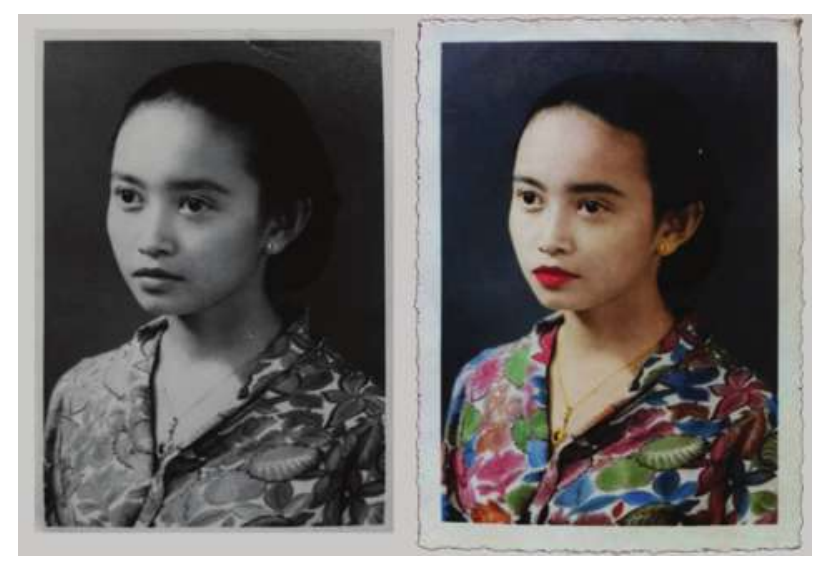

Gambar 6. Foto hitam putih dan foto 'berwarna' hasil tusir/hand coloring koleksi keluarga Kartosoedarmo, Yogyakarta, 1954 (Reproduksi: Irwandi).

Sebagian besar pemilik studio foto lebih memandang fotografi sebagai bisnis yang menguntungkan. Maksudnya, dengan memiliki studio foto tidak berarti mereka juga memiliki hobi fotografi. Oleh karena itu, dapat dimaklumi jika tidak ada seorang pun dari mereka yang bergabung dengan klub HISFA (Himpunan Seni Foto Amatir) Yogyakarta, yang didirikan pada tahun 1954 di Yogyakarta. Artinya para pemilik studio secara artistik tidak banyak dipengaruhi oleh fotografer-fotografer amatir saat itu. Sebagaimana dituturkan oleh Leonardus.

$$
\text { Iya, saya inget betul itu, }
$$
dia salah satu ya, Hwa Sin itu top terus dia itu sebenernya keluarga, dan itu bukan hobi foto tapi untuk cari duit. Kalok kakek-kakeknya kebanyakan iya. Jadi, prinsipnya itu pokoknya mereka itu fotografi untuk cari nafkah, kalok mereka itu, jadi bukan foto-foto seniman foto gitulah gampangnya gitu loh, atau hobi, mereka harus cari duit gimana? Ya udah belajar motret (Suljantoro, 8 Oktober 2013).

Namun, tanpa adanya hobi fotografi, pada kenyataannya tetap saja ada unsur kreativitas dalam upaya mempermudah 
pekerjaan dan menghasilkan foto yang disukai konsumen. Salah satunya terlihat dari upaya mereka untuk menghasilkan lembaran foto berpermukaan mengilap (glossy).

Pada saat itu mereka hanya memiliki kertas berpermukaan tidak mengilap (dof). Kertas glossy masih sulit ditemukan sehingga mereka mencari cara agar dapat menghasilkan foto glossy tanpa harus membeli kertas glossy. Akhirnya mereka memang berhasil menemukan caranya, yaitu dengan meletakkan foto di atas landasan kaca dengan posisi emulsi (bagian gambar menghadap ke kaca), lalu ditutup dengan kain, kemudian digosok dari atas dengan bantuan kayu bulat selama beberapa menit (Wawancara dengan Melliana Oetomo, penerus Studio Shanghai (sekarang Delanggu Foto), Delanggu, 10 September 2013).

Namun, sebelum pekerjaan tersebut dilakukan kaca yang menjadi landasan harus dibersihkan terlebih dahulu dengan menggunakan cairan spiritus dan bedak. Inilah jawaban atas pertanyaan, mengapa lembaran foto-foto glossy pada masa tersebut terlihat lebih tipis daripada lembaran foto dof. Ternyata tekanan kayulah yang menyebabkan foto menjadi glossy. Sebagaimana dijelaskan sebagai berikut.

...ini kaca, ini foto. Fotone (fotonya) ditemplekke kaca, fotonya ke bawah (menghadap kaca), tapi sebelumnya kacanya dibersihkan dulu, dilap, dikasih spirtus, dikasih bedak terus sampe bersih. Nah fotonya itu nempel ke kaca... habis itu ditutup kain, habis itu digosok. Sampai kering nanti fotonya nemplek di kaca, habis itu dikeringke. Tapi nggak dijemur lho, dianginangin aja... nanti jatuh sendiri, jatuh sendiri jadi mengkilap. Akal-akalan sendiri. Itu kacae (kacanya) harus bersih. Nggak boleh kena tangan, kena minyak (Wawancara dengan Ana Soetomo dan Tri Poernomo, Pemilik Shanghai Foto (sekatang Delanggu foto), 10 September 2013).

Format foto sebelum dekade 70-an sebenarnya sudah bervariasi. Berdasarkan fotofoto yang didapat, ukuran foto yang ditemukan mulai dari yang terkecil, adalah: $2 \mathrm{X} 3(2,5 \mathrm{~cm}$

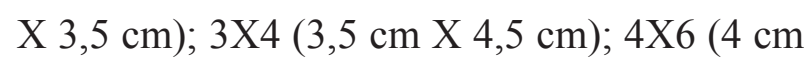
$\mathrm{X} 5,5 \mathrm{~cm}) ; 6 \mathrm{X} 9(5,4 \mathrm{~cm} \mathrm{X} 8 \mathrm{~cm})$; ukuran post card (9 cm X 12,7 cm); ukuran 10R (17 cm X $22,8 \mathrm{~cm})$. Ukuran-ukuran tersebut merupakan ukuran yang lazim ditemukan. Namun, pada kenyataannya selalu terdapat selisih ukuran beberapa milimeter di tiap golongan ukuran foto. Sebagai contoh, sering kali ditemukan adanya ukuran yang berlainan di dua foto yang sama-sama disebut foto 4 X 6. Selisih ukuran ini bisa terjadi karena proses cetak dan pemotongan kertas pada masa itu belum dilakukan secara masinal. Ciri lain yang terlihat pada foto-foto sebelum dekade 70-an ialah garis tepi yang berupa area putih di sekeliling foto. Sering kali pula garis tepi tersebut berkontur porporasi di bagian luar, yang terbentuk dari mata pisau alat pemotong kertas.

Foto-foto yang telah selesai dikerjakan kemudian disimpan di dalam album foto yang umumnya terbuat dari kertas manila berwarna hitam, yang di tiap lembarnya dilapisi dengan kertas minyak. Pelapisan demikian sebenarnya dilakukan untuk menyekat tiap lembaran album dan memiliki tujuan tertentu. Tujuannya supaya permukaan foto-foto yang disimpan di dalam album tidak saling menempel. 


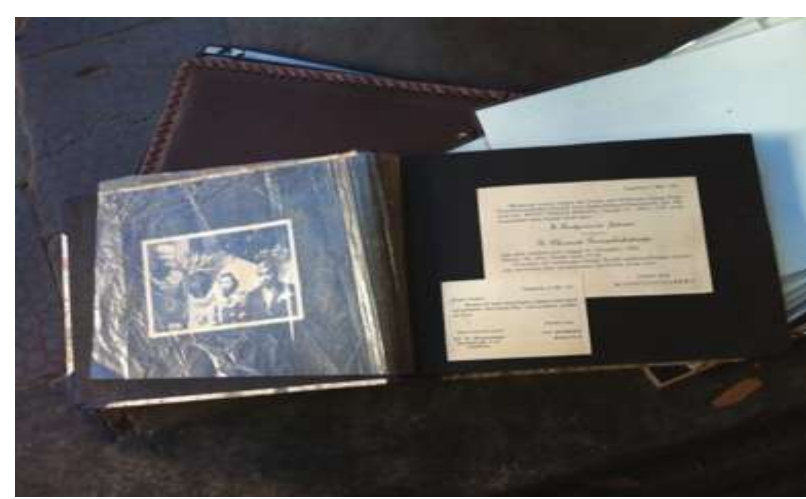

Gambar 7. Album foto tampak dalam, milik keluarga Kartosoedarmo, Yogyakarta, 1956

(Foto: Irwandi)

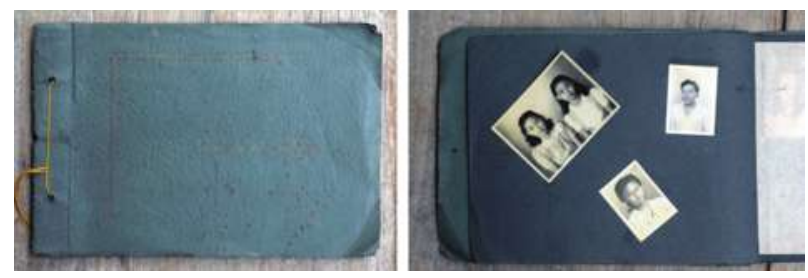

Gambar 8. Album foto tampak luar dan dalam, koleksi Angki Purbandono.

(Foto: Joko Suwarno)

Pose subjek dalam foto-foto potret dekade 60-70-an yang ditemui umumnya tampak statis dan 'biasa'. Pose berdiri menghadap kamera disertai dengan variasi $3 / 4$ profil tampak dominan dalam foto potret masa itu. Selain berpose berdiri, tidak sedikit pula pose-pose yang agak sedikit santai. Misalnya sambil duduk di kursi, baik menatap kamera maupun menatap ke tempat lain. Yang jelas, kesan kesempurnaan tampilan sangat terasa dalam foto. "Posenya ya masih zaman kuno dulu ya masih biasa saja, pokoknya ya cuma miring, tangan di pinggang, ya simple lah" (Wawancara dengan Yulianto Lie, pemilik Kencana Foto Yogyakarta, 6 Februari 2014).

Kemeja, kebaya, dan pakaian kasual menjadi kostum yang umum dalam foto potret masa itu. Menurut Handoyo, keistimewaan sitter beserta pakaiannya haruslah ditampilkan (ditonjolkan). Sebagaimana penuturannya, "Pake motor ya biasanya, itu kalok jam tangan gayanya mesti gini (tangan dilipat di depan badan), dulu kan jam tangan mewah banget" (Handoyo, 1 Oktober 2013).

Pose-pose yang diperagakan sitter potret pada masa itu lebih banyak diatur oleh fotografer. Jadi, ada kesan seolah-olah pihak studiolah yang paling menentukan tampilan akhir sebuah foto potret. Walaupun di balik itu, sebenarnya proses penentuan dapat berlangsung dialogis. Para fotografer di studio bahkan cukup peka dengan selera konsumen sehingga diharapkan mampu menghasilkan foto potret yang memuaskan masing-masing konsumen. Hanya saja, proses penentuan dialogisnya memang tidak terjadi secara langsung, tetapi melalui proses evaluasi internal studio foto, sebagaimana dikatakan Strassler: "Mereka lihat-lihat yang disukai konsumen. Oh... yang laku gambar latar ini.. yang ini ngga terlalu... jadi mereka lihat itu" (Karen Strassler, Kuliah Umum di Program Studi Fotografi, ISI Yogyakarta, 16 Mei 2013).

Latar belakang polos, draperi, dan lukisan arsitektur serta pemandangan alam tropis sering dipergunakan. Gambar-gambar latar itu tampak dominan atau menonjol, seolaholah sama kuatnya dengan subjek foto. Menurut pengamatan Strassler, gejala penggunaan gambar latar semacam itu terlihat pada dekade akhir 50-an. Hal demikian terjadi karena pada kenyataannya konsumen foto lebih menyukai gambar latar yang ramai, jelas, tegas, dan lengkap. Kondisinya memang berbeda dengan masa sebelumnya, yaitu masa prakemerdekaan, yang pada umumnya gambar latar dibuat lebih samar seakan-akan menyesuaikan dengan prinsip depth of field atau ruang ketajaman gambar dalam ilmu fotografi.

Varian produk foto yang ditawarkan tentu saja belum sebanyak sekarang. Studio- 
studio foto hanya menggunakan istilah pasfoto, foto setengah badan, foto seluruh badan, dan foto keluarga. Jadi, dapat diartikan bahwa fotofoto pada masa itu, kecuali foto keluarga, dibuat dan diklasifikasikan berdasarkan kriteriakriteria teknis; tidak berdasarkan tema ataupun subject matter di dalamnya.

Informasi mengenai harga pasti untuk jasa dan produk foto potret pada era 60-70'an tidak berhasil didapatkan. Para pelaku usaha studio foto dan para pengguna jasa studio mereka sudah tidak lagi mengingatnya. Satusatunya sumber yang dapat menjadi gambaran harga ialah nota order sekaligus amplop cetak foto di Studio Metro Klaten yang bertahun 1967. Dalam nota tersebut tertera jasa Afdruk (cetak 1:1) berbiaya Rp100,00, dikerjakan selama 10 hari.

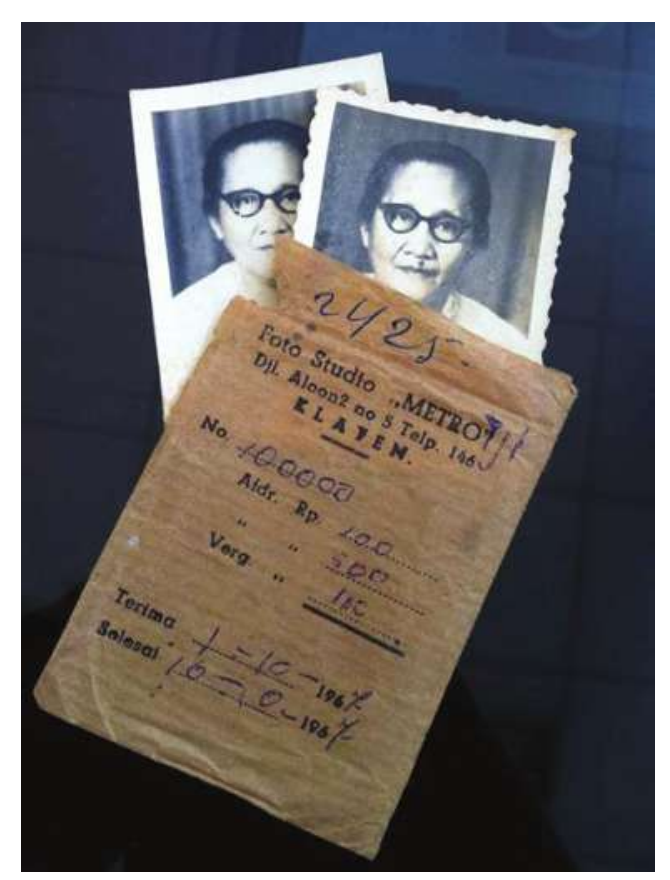

Gambar 9. Amplop foto Studio Metro Klaten pada tahun 1967, koleksi Oscar Samaratungga.

(Foto: Irwandi)

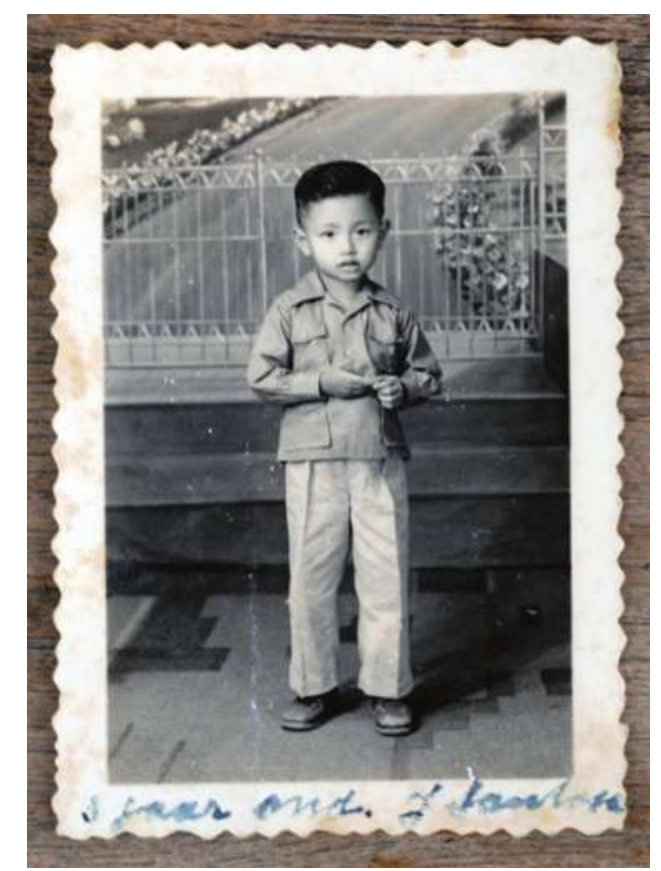

Gambar 10. Foto potret anak di Studio Hwa Sin, Yogyakarta, sekitar tahun 1960, koleksi Angki Purbandono.

(Foto: Joko Suwarno)

\section{SIMPULAN}

Paparan mengenai sejarah singkat studio foto di Yogyakarta di bagian terdahulu setidaknya menunjukkan bagaimana faktor teknologi dan sumber daya manusia berpengaruh sangat besar dalam membentuk wujud karya fotografi di masyarakat. Saat bisnis studio foto masih berbasis bisnis keluarga, masyarakat sebagai konsumen belum punya banyak pilihan selain mengikuti arahan fotografer di studio. Atau, mereka akan mendapatkan foto yang gagal secara teknis. Belum lagi yang berkaitan dengan waktu tunggu yang cukup lama untuk mendapatkan selembar cetakan foto. Proses kamar gelap seolah menjadi dinding yang sangat kokoh sehingga ada jarak antara produsen dan konsumen. Hal itu pula yang menyebabkan tingkat kebergantungan konsumen terhadap studio foto sangat tinggi. Keadaan demikian sangat kontras dengan keadaan sekarang.

Hasil penelusuran sejarah praktik potret di Yogyakarta ini, selain dapat dijadikan 
rujukan penelusuran sejarah secara lebih dalam, juga dapat dijadikan acuan untuk membahas lebih lanjut proses kreasi artistik dalam karyakarya fotografi yang dihasilkan melalui praktik studio potret di Yogyakarta.

\section{KEPUSTAKAAN}

Groeneveld, Anneke. 1989. "Photography in Aid of Science", dalam Anneke Groeneveld (Ed.), Toekang Potret: 100 Jaar Fotografie in Nederlandss-Indië. Amsterdam: Fragmen.

Knapp, Gerrit. 1999. Céphas, Yogyakarta: Photography in the Service of the Sultan. Leiden: Koninklijk Instituut Voor Taal-, Land- en Volkenkunde.

Strassler, Karen. 2010. Refracted visions:

Popular photography and national modernity in Java. Durham and London: Duke University Press.

Haks, Leo dan Steven Wachlin. 2004. Indonesia: 500 Early Postcards. Singapore: Archipelago Press.

Marah, Risman (ed.). 2008. Soedjai Kartasasmita dalam Belantara Fotografi Indonesia. Yogyakarta: BP ISI Yogyakarta.

Soedjono, Soeprapto, Surisman Marah, Edial Rusli. 1999. "Tinjauan Fotografi Salon Foto Indonesia dalam Konteks Pengembangan Seni Budaya Nasional". Laporan Penelitian. Yogyakarta: Lembaga Penelitian ISI Yogyakarta.

\section{Informan}

Agus Leonardus Sujantoro, fotografer, wawancara dengan penulis, 8 Oktober 2013.

Ana Soetomo dan Tri Poernomo, Pemilik Shanghai Foto (sekatang Delanggu foto), wawancara dengan penulis, 10 September 2013.

Cung Mintarto, penerus studio Tik Sun, pemilik Menara Foto, Wonogiri, wawancara dengan penulis, 21 Oktober 2013.

Gianti Indartini, pendiri Studio Tik Sun, wawancara dengan penulis, 1 Oktober 2013.
Herri Gunawan, pemilik Studio Herry Photo, wawancara dengan penulis 30 September 2013.

Johnny Hendarta, pemilik Studio CPC Yogyakarta, wawancara dengan penulis, 22 Januari 2014.

Karen Strassler, Kuliah umum di Program Studi Fotografi, ISI Yogyakarta, 16 Mei 2013

Melliana Oetomo, penerus Studio Shanghai (sekarang Delanggu Foto), Delanggu, wawancara dengan penulis, 10 September 2013.

Sapto Handoyo, pemilik Artha Foto, wawancara dengan penulis, 1 Oktober 2013.

Stephanus Setiawan, Praktisi fotografi, wawancara dengan penulis, 27 September 2013.

Tri Poernomo Oetomo, Penerus Shanghai foto (sekarang Delanggu Foto), wawancara dengan penulis, 10 September 2103.

Yulianto Lie, pemilik Kencana Foto Yogyakarta, wawancara dengan penulis, 6 Februari 2014. 
